Arq. Bras. Med. Vet. Zootec., v.67, n.5, p.1287-1294, 2015

\title{
Conformação de úbere de caprinos da raça Saanen: parâmetros estéticos ou funcionais?
}

\author{
[Udder conformation of Saanen goats: aesthetic or functional parameters?] \\ D.S. Santos ${ }^{1}$, M.G.B. Lima ${ }^{1}$, C.F. Noznica ${ }^{2}$, D.M. Lima ${ }^{3}$, C.F. Batista ${ }^{4}$, R.C. Gomes ${ }^{4}$, \\ H.G. Bertagnon ${ }^{5}$, B.P. Santos ${ }^{6}$, A.M.M.P. Della Libera ${ }^{7}$ \\ ${ }^{1}$ Médica veterinária autônoma \\ ${ }^{2}$ Zootecnista autônoma \\ ${ }^{3}$ Aluno de graduação - Faculdade de Medicina Veterinária e Zootecnia - USP - São Paulo, SP \\ ${ }^{4}$ Aluno de pós-graduação - Faculdade de Medicina Veterinária e Zootecnia - USP - São Paulo, SP \\ ${ }^{5}$ Escola de Medicina Veterinária e Zootecnia - UNICENTRO - Guarapuava, PR \\ ${ }^{6}$ Aluno de pós-graduação - Universidade Estadual de Londrina - Londrina, PR \\ ${ }^{7}$ Faculdade de Medicina Veterinária e Zootecnia - USP - São Paulo, SP
}

\begin{abstract}
RESUMO
Diversos fatores predisponentes são descritos para as afecções mamárias ou distúrbios secundários que comprometem a qualidade e produtividade de leite de fêmeas nas diferentes espécies. As características fenotípicas do úbere são consideradas na avaliação econômica de uma fêmea caprina, tanto pelo potencial de produção como pelo registro genealógico dessa fêmea. A limitação de estudos correlacionando essas características com a saúde do úbere gera a dúvida a respeito do significado da conformação do mesmo à saúde e produtividade da glândula mamária. Sendo assim, este estudo teve como objetivo relacionar os parâmetros da conformação do úbere com a celularidade da glândula mamária aferida pelo teste California Mastitis Test (CMT) e contagem de células somáticas (CCS) em 80 cabras da raça Saanen sem alterações no exame clínico da glândula mamária nem no teste de Tamis. Observou-se que a maioria dos parâmetros fenotípicos de úbere não influenciou a CCS, sendo considerados puramente estéticos. A circunferência e profundidade de úbere demonstraram correlação negativa com a celularidade e, por serem características de herdabilidade moderada a alta, podem ser parâmetros considerados para seleção genética de caprinos.
\end{abstract}

Palavras-chave: cabra, contagem de células somáticas, qualidade do leite, glândula mamária

\begin{abstract}
Several predisposing factors are described for mammary diseases or secondary disorders that compromise the quality and productivity of milk from females in different species. The phenotypic characteristics of the udder are considered in the economic evaluation of a female goat, whether for production potential, or as the genealogical record for these females. The limitation of studies correlating these features with the udder health raises doubt about the meaning of the conformation to the health and productivity of the mammary gland. Therefore, this study aimed to list the parameters of the udder conformation with the cellularity of the mammary gland checked by California Mastitis Test (CMT) and somatic cell count (SCC) in 80 Saanen goats without alterations in the clinical examination of the mammary gland or the Tamis test. It was observed that most of the phenotypic parameters of the udder did not influence the CCS, being considered purely esthetic. The circumference and udder depth showed negative correlation with the cellularity and moderate to high heritability traits can be considered parameters for genetic selection of goats.
\end{abstract}

Keywords: goat, somatic cell count, milk quality, mammary gland

Recebido em 4 de março de 2015

Aceito em 18 de junho de 2015

*Autor para correspondência (corresponding author)

E-mail: camilafb@usp.br 


\section{INTRODUÇÃO}

No Brasil, existem cerca de 9,3 milhões de caprinos (IBGE, 2010), sendo ainda inexpressiva a produção de leite por essa espécie animal, cerca de $30 \mathrm{~kg} / \mathrm{animal} / \mathrm{ano}$. Tal fato se deve à baixa qualidade genética dos rebanhos, manejo alimentar deficiente, alto índice de doenças e uso de instalações inadequadas para a obtenção e manuseio do leite (Brasil, 2006).

A higidez do animal, em especial da glândula mamária, é um dos fatores que contribuem diretamente no volume e qualidade do leite produzido (Souza et al., 2007; Della Libera et al., 2011). Várias técnicas para detectar a inflamação da glândula mamária têm sido estudadas, sendo as mais aceitas o California Mastitis Test (CMT), pela praticidade a campo, e a Contagem de Células Somáticas (CCS), em razão de sua sensibilidade e especificidade (Paape et al., 2007; Mira et al., 2013).

Diferentemente do bovino sadio, as células somáticas normalmente são numerosas no leite de cabra, já que o tipo de secreção láctea é apócrina. A glândula mamária dos caprinos pode eliminar o produto de secreção junto com parte da célula secretória (Zeng, 1996), resultando em grande variação na contagem de células somáticas, considerando-se limites fisiológicos de 50.000 a 400.000 células $/ \mathrm{mL}$ (Souza et al., 2007).

No Brasil não há limites máximos oficiais exigidos para a comercialização do leite de cabra baseados na CCS, mas a globalização dos mercados indica que medidas regulamentares nesse sentido são iminentes (Magalhães, 2005). Como a CCS está intimamente ligada à qualidade do leite e saúde do úbere, torna-se importante envidar esforços para reduzir o atual padrão de 1.000 .000 células $/ \mathrm{mL}$, limite regulamentado para rebanhos tipo A nos Estados Unidos (Souza et al., 2007).

A conformação de úbere já foi correlacionada com a CCS em bovinos (Dube et al., 2009), ovinos (Casu et al., 2006) e caprinos mestiços (Montaldo e Martínez-Lozano, 1993). Szymanowska et al. (2010) obtiveram correlações fortes e positivas entre a produção diária de leite e os seguintes parâmetros de úbere: circunferência do úbere, medição medial do úbere e diâmetro dos tetos; e uma correlação forte e negativa entre a produção diária de leite e distância do assoalho do úbere até o solo em caprinos da raça Saanen. Sabe-se que significativas relações genéticas têm sido relatadas em alguns parâmetros de conformação de úbere e CCS (Rupp e Boichard, 1999), e a herdabilidade dessas características já foi estabelecida para caprino da raça Saanen por Rupp et al. (2011), apresentando-se como moderada a alta, o que possibilita a seleção genética de cabras com base na conformação de úbere.

Essas conformações são analisadas e utilizadas atualmente como critério para registro genealógico dos caprinos, baseado principalmente no aspecto estético, não havendo um estudo comprobatório que relacione essas conformações com a saúde do úbere. Portanto, é importante estabelecer a correlação entre conformação de úbere e celularidade da glândula mamária em caprinos, permitindo selecionar caprinos com parâmetros genéticos condizentes com produção de leite de melhor qualidade.

\section{MATERIAL E MÉTODOS}

Este projeto foi protocolado sob o número 1684/2009 no Comitê de Ética no Uso de Animais (CEUA) da Faculdade de Medicina Veterinária e Zootecnia da Universidade de São Paulo.

$\mathrm{O}$ experimento foi realizado nos meses de maio e junho de 2011, utilizando 80 cabras da raça Saanen em lactação, provindas de dois rebanhos comerciais produtores de leite, não considerando estágio ou número de lactações, nem idade dos animais. Foram considerados como critérios de exclusão alterações no exame físico da glândula mamária de acordo com o preconizado por Birgel (2005) e a positividade no teste de Tamis (teste do fundo escuro).

Para a avaliação da conformação do úbere, os animais foram mantidos em estação no período antecedente à ordenha, em terreno livre de inclinação e utilizando-se uma fita métrica; foram obtidas as medições seguindo os parâmetros descritos por Montaldo e MartínezLozano (1993), demonstrados na Figura 1 e explicados a seguir. 


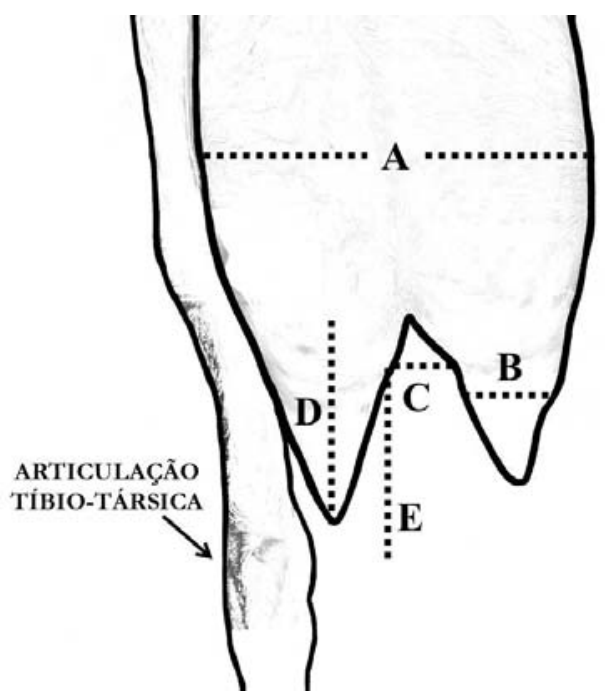

Figura 1. Critérios para medição do úbere caprino, aspecto caudocranial do úbere: A, circunferência de úbere $(\mathrm{CU})$; B, diâmetro de teto $(\mathrm{DmT})$; C, distância entre os tetos $(\mathrm{DT})$; D, comprimento de teto $(\mathrm{CT})$; E, profundidade de úbere $(\mathrm{PU})$.

- Diâmetro de teto (DmT): medição da porção média do teto;

- Comprimento de teto (CT): medição a partir da base até a extremidade do teto;

- Distância entre os tetos (DT): medição entre a base dos dois tetos;

- Distância do teto até o solo (DTS): medição entre a extremidade do teto até o solo;

- Circunferência de úbere (CU): medição horizontal do úbere, realizada na porção média do úbere;

- Medição medial do úbere (MMU): medição vertical do úbere, a partir da inserção medial cranial até a inserção medial caudal, passando na região do ligamento suspensório medial;

- Profundidade do úbere (PU): medição entre o ponto mais ventral do assoalho do úbere até o solo subtraindo-se a medição entre a articulação tibiotársica e o solo.

Agruparam-se as 80 cabras da raça Saanen em dois grupos, de acordo com a profundidade do úbere, para a comparação das médias de celularidade das glândulas mamárias. $\mathrm{O}$ grupo 1 referiu-se a cabras que apresentaram assoalho de úbere abaixo da articulação tibiotársica; e o grupo 2, as com assoalho de úbere acima dessa articulação.

A avaliação da celularidade do leite foi realizada pela Clínica do Leite - ESALQ/USP, Laboratório de referência em Análise da Qualidade do Leite, utilizando a referência de leite bovino. Nesse quesito, foi realizada a contagem indireta em simplicata por meio do CMT e por CCS, a partir de frascos contendo o leite caprino coletado e conservante bronopol.

Para a análise estatística, atribuem-se escores aritméticos aos resultados de CMT, sendo $0,1,2$, 3 e 4 para as reações negativas, traços, $1+, 2+$ e $3+$, respectivamente. Os valores de CCS foram transformados em logaritmo natural para obter a normalidade da distribuição para análise.

Os coeficientes de correlação (r) foram interpretados como fraca uma correlação no intervalo de $0<\mathrm{r} \leq 0,3$; moderada de $0,3<\mathrm{r} \leq$ 0,6 ; e forte de $0,6<\mathrm{r} \leq 1$. As correlações foram consideradas significativas quando $\mathrm{P} \leq 0,05$.

Para análise estatística, realizaram-se testes de correlação entre as variáveis e teste t para duas amostras independentes com o software SPSS Statistics.

\section{RESULTADOS}

Os dados obtidos dos parâmetros de conformação de úbere de caprinos da raça Saanen estão demonstrados na Tabela 1 . 
Tabela 1. Mensuração dos parâmetros de conformação de úbere de cabras da raça Saanen, em centímetros

\begin{tabular}{lccc} 
Variável & $\mathrm{N}$ & Média & Desvio Padrão \\
\hline DmT & 160 & 11,60 & 3,90 \\
CT & 160 & 8,01 & 1,69 \\
DTS & 160 & 22,65 & 4,35 \\
DT & 80 & 10,34 & 3,14 \\
CU & 80 & 50,81 & 6,39 \\
MMU & 80 & 39,03 & 5,58 \\
PU & 80 & 0,56 & 4,00 \\
\hline
\end{tabular}

DmT: diâmetro de teto; CT: comprimento de teto; DTS: distância do teto até o solo; DT: distância entre os tetos; CU: circunferência de úbere; MMU: medição medial de úbere; PU: profundidade de úbere.
As correlações entre a celularidade da glândula mamária, aferida por $\mathrm{CMT}$ ou $\mathrm{CCS}$, e os parâmetros de conformação de úbere encontramse nas Tabelas 2 e 3, não havendo significância estatística para a maioria das variáveis. Foram encontradas correlações positivas e fracas para as variáveis: CMT e distância entre os tetos, CMT e diâmetro de teto, CCS e diâmetro do teto apenas no lado direito. Houve correlação negativa e fraca entre CMT e comprimento de teto, CMT e distância do teto esquerdo até o solo, CCS e comprimento de teto, CCS e distância do teto até o solo, CMT e medição medial de úbere, CCS e distância entre os tetos, CCS do teto direito e medição medial de úbere, $\mathrm{CCS}$ do teto direito e profundidade de úbere.

Tabela 2. Correlação entre os parâmetros dos tetos, CMT e CCS em caprinos da raça Saanen

\begin{tabular}{llllllllllll} 
& Variável & CMT & $P$ & CCS & $P$ & & Variável & CMT & $P$ & CCS & $P$ \\
\hline Teto & DmT & 0,047 & 0,681 & $-0,004$ & 0,974 & Teto & DmT & 0,008 & 0,944 & 0,039 & 0,739 \\
esquerdo & CT & $-0,126$ & 0,265 & $-0,131$ & 0,259 & direito & CT & $-0,156$ & 0,168 & $-0,07$ & 0,545 \\
& DTS & $-0,181$ & 0,109 & $-0,039$ & 0,738 & & DTS & $-0,277$ & 0,013 & $-0,099$ & 0,394 \\
\hline
\end{tabular}

DmT: diâmetro de teto, CT: comprimento de teto, DTS: distância do teto até o solo.

Tabela 3. Correlação entre os parâmetros de conformação de úbere, CMT e CCS em caprinos da raça Saanen

\begin{tabular}{lllllllllllll}
\hline & Variável & CMT & $P$ & CCS & $P$ & Variável & CMT & $P$ & CCS & $P$ \\
\hline Teto & DT & 0,098 & 0,388 & $-0,041$ & 0,724 & Teto & DT & 0,151 & 0,181 & $-0,072$ & 0,536 \\
esquerdo & CU & $-0,42$ & 0000 & $-0,48$ & 0000 & direito & CU & $-0,392$ & 0000 & $-0,408$ & 0000 \\
& MMU & $-0,186$ & 0,098 & $-0,225$ & 0,05 & & MMU & $-0,163$ & 0,149 & $-0,21$ & 0,067 \\
& PU & $-0,245$ & 0,029 & $-0,092$ & 0,431 & & PU & $-0,342$ & 0,002 & $-0,111$ & 0,338
\end{tabular}

DT: distância entre os tetos, CU: circunferência de úbere, MMU: medição medial de úbere, PU: profundidade de úbere.

Houve correlação negativa, fraca e significativa entre CMT e distância do teto até o solo apenas no teto direito, CMT e profundidade de úbere, CCS do teto esquerdo e medição medial de úbere. Houve correlação negativa, moderada e extremamente significativa entre CMT e circunferência de úbere, CCS e circunferência de úbere.

As médias em logaritmo de CCS dos grupos 1 e 2 estão apresentadas na Tabela 4.

As cabras com assoalho de úbere mais próximo ao solo (grupo 1) possuíam maior celularidade em relação às cabras com assoalho de úbere acima da articulação tibiotársica (grupo 2) com uma diferença extremamente significativa. No entanto, no diagrama de dispersão (Fig. 2), a celularidade da glândula mamária por animal não seguiu um padrão, havendo valores altos nos dois grupos, e um número pequeno de animais com celularidade mais elevada (entre 5 a 7 milhões de células/mL) no grupo 1 .

Tabela 4. Médias em logaritmo de CCS dos Grupos1 e 2 de acordo com a profundidade de úbere em caprinos da raça Saanen

\begin{tabular}{lll}
\hline Grupo & Média da CCS $\left(\log _{10}\right)$ & $P$ \\
\hline 1 & 2,785 & 0,004 \\
2 & 2,368 &
\end{tabular}




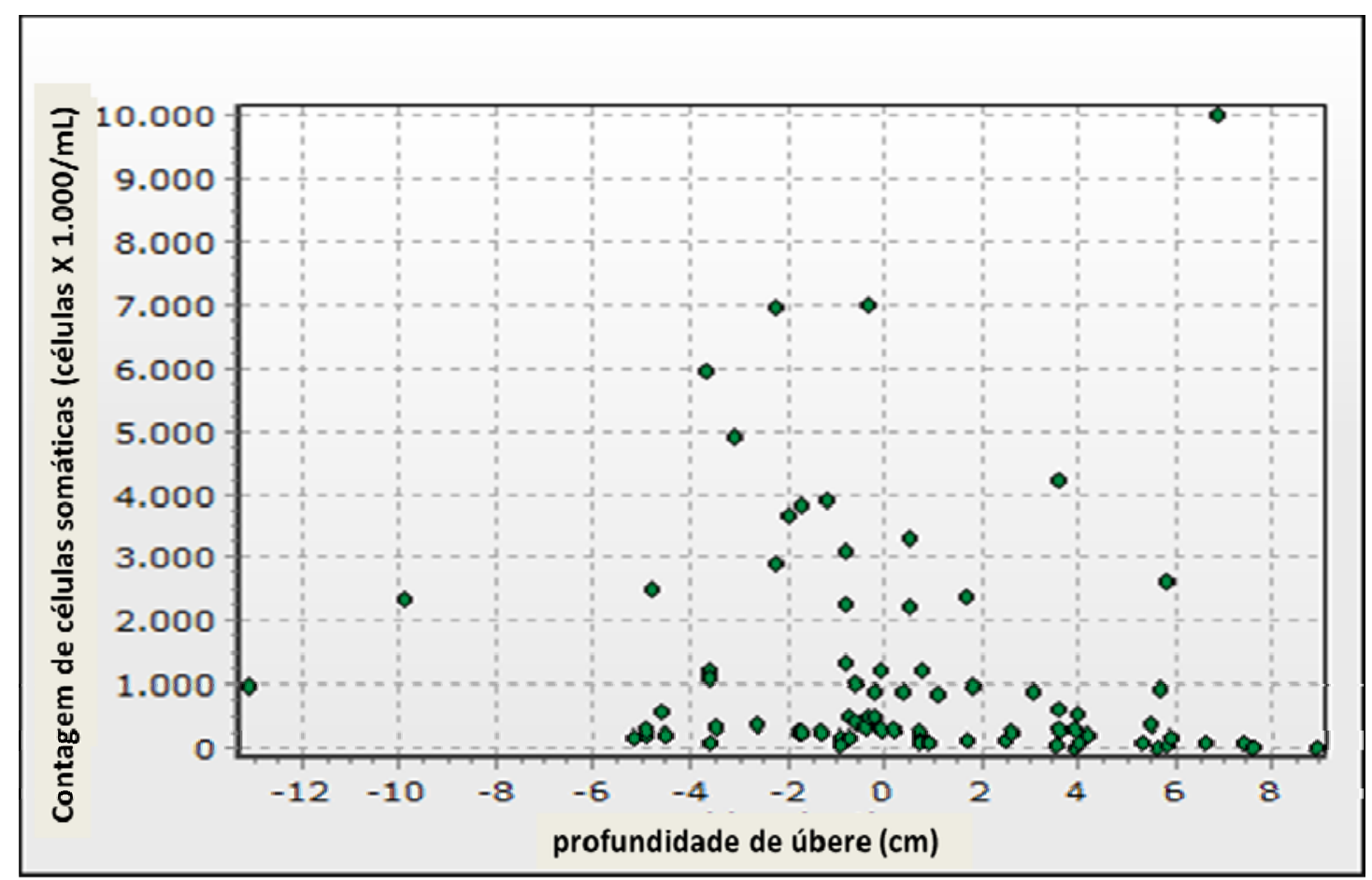

Figura 2. Diagrama de dispersão CCS x PU de 80 cabras da raça Saanen

\section{DISCUSSÃO}

O presente estudo procurou estabelecer critérios para avaliação da conformação de úbere de cabras da raça Saanen e demonstrou que a maioria dos parâmetros de conformação de úbere avaliados não influenciou na contagem de células somáticas, discordando dos achados da literatura compilada de bovinos, ovinos e caprinos (Montaldo e Martínez-Lozano, 1993; Casu et al., 2006; Dube et al., 2009).

As médias de circunferência de úbere, medição medial de úbere e distância entre os tetos foram inferiores às encontradas por Szymanowska et al. (2010), diferentemente das médias de comprimento de teto e diâmetro de teto que foram superiores às encontradas por Manfredi et al. (2001), Szymanowska et al. (2010) e Rupp et al. (2011) em caprinos da raça Saanen. No presente trabalho, não foi considerado o fator idade para as cabras avaliadas, aspecto importante, pois o envelhecimento causa progressivo alargamento do úbere, com relaxamento de seus ligamentos (Szymanowska et al., 2010), fato que poderia explicar as divergências entre as mensurações encontradas para animais da mesma raça.
Assim como Montaldo e Martínez-Lozano (1993), o presente trabalho encontrou correlação negativa significativa entre CMT/CCS e circunferência de úbere. Szymanowska et al. (2010) notaram que cabras com maior circunferência de úbere apresentavam maior produtividade de leite. Como a produção leiteira está correlacionada também com a saúde do úbere (Souza et al., 2007), possivelmente a conformação de úbere redunda em menor predisposição à inflamação da glândula mamária, seja por trauma ou por infecção, resultando em menor CCS e maior produção de leite.

As demais correlações significativas (CMT e distância do teto direito até o solo, CCS do teto esquerdo e medição medial de úbere e CMT e profundidade de úbere) foram fracas e a maioria delas se manifestou em apenas um dos antímeros. Além disso, não houve similaridade entre os comportamentos de CMT e CCS. Esses dois testes aferem a CCS da glândula mamária e, portanto, costumam mostrar resultados semelhantes, mesmo sendo o teste do CMT menos sensível (Paape et al., 2007). Assim, acredita-se que esses parâmetros não interferem na celularidade do úbere. 
Da mesma forma, Montaldo e Martínez-Lozano (1993) e Rupp et al. (2011) encontraram correlações significativas de maneira semelhante a esta pesquisa, manifestadas somente no teste de CCS ou no CMT ou em apenas um antímero.

Todos esses resultados isolados podem ser explicados pelo fato de não ser possível limitar um fator, no caso só a conformação de úbere, como o responsável pela magnitude de celularidade da glândula mamária. Vários fatores podem influenciar a CCS, como idade e estado fisiológico do hospedeiro, antecedentes e estágio de infecção, patógeno e fase de lactação (Gomes et al., 2006; Paape et al., 2007; Koop et al., 2010).

Pesquisadores têm buscado correlacionar parâmetros de conformação de úbere e produção de leite. Contudo, a produção de leite também é influenciada por diversos fatores, como tipo de sistema de produção, estágio de lactação, parição, persistência de lactação, número de ordenhas/dia, fatores genéticos, saúde da glândula mamária e nutrição (Montaldo et al., 2010; Tovar-Luna et al., 2010; Goetsch et al., 2011).

$\mathrm{Na}$ literatura encontram-se resultados diversos sobre correlação de conformação de úbere tanto com CCS quanto com produção de leite. Mavrogenis et al. (1989) encontraram uma baixa correlação entre produção de leite e medidas de úbere, enquanto outros encontraram correlações mais altas e significativas (Peris et al., 1999). Capote et al. (2006) demonstraram que a morfologia de úbere possui uma maior influência na produção de leite quando as cabras são ordenhadas duas vezes ao dia em comparação com uma vez ao dia.

Possivelmente o estabelecimento de um grupo mais homogêneo de animais, reduzindo-se fatores de interferência, como animais infectados e não infectados, considerar antecedentes de traumas ou infecção, e utilização de cabras que estejam no mesmo estágio de lactação, possa fornecer resultados mais confiáveis com relação à CCS.

Quanto à correlação entre a profundidade de úbere e CCS, observou-se oscilação dos valores encontrados tanto para cabras com úberes de maior profundidade quanto para cabras com úberes de menor profundidade. Esse fato pode ter ocorrido por diversos fatores, como antecedentes de traumas, presença, estágio e gravidade de infecção e estágio e número da lactação (Koop et al., 2010). Como as cabras avaliadas no presente estudo tiveram poucos critérios de exclusão, estavam sujeitas a todas essas alterações. $\mathrm{O}$ foco do trabalho foi estudar conformação de úbere na população geral de cabras da raça Saanen no Estado de São Paulo, também sujeitas a essas intercorrências, portanto os critérios atribuídos na pesquisa foram suficientes para essa avaliação.

Embora tenha sido encontrada oscilação entre os valores de CCS para os dois grupos de cabras, verificou-se que cabras com úberes acima da articulação tibiotársica (mais profundos) possuíam uma menor celularidade, estando esses achados de acordo com Rupp e Boichard (2003) e Rupp et al. (2011). Com base nisso, uma seleção genética de cabras com úberes mais inseridos e, portanto, profundos, favoreceria uma menor celularidade; contudo úberes com essa característica são associados a uma menor produção de leite (Manfredi et al., 2001; Capote et al., 2006; Clement et al., 2006). Portanto, a seleção genética de cabras com úberes mais profundos deve ser criteriosamente estudada a fim de não reduzir a produtividade dos animais.

\section{CONCLUSÃO}

A maioria dos parâmetros de conformação de úbere analisados foram puramente estéticos ao considerar uma população geral de cabras da raça Saanen. Nessas condições, ressalta-se que a circunferência e profundidade de úbere têm correlação negativa com $\mathrm{CCS}$ e, por serem características de herdabilidade moderada a alta, podem ser parâmetros considerados para seleção genética de caprinos.

\section{AGRADECIMENTOS}

À Fundação de Amparo à Pesquisa do Estado de São Paulo (FAPESP) pela concessão do auxílio à pesquisa 2010/ 07716-3 e pela concessão da bolsa de iniciação científica FAPESP2010/18053-5. 


\section{REFERÊNCIAS}

BIRGEL, E. H. Semiologia da glândula mamária de ruminantes. In:FEITOSA, F.L.F. (Ed.); Semiologia veterinária: a arte do diagnóstico. São Paulo: Roca, 2005. p.353-399.

CAPOTE, J.; ARGÜELlO, A.; CASTRO, N. et al. Correlations between udder morphology, milk yield, and milking ability with different milking frequencies in dairy goats. J. Dairy Sci., v.89, p.2076-2079, 2006.

CASU, S.; PERNAZZA, I.; CARTA, A. Feasibility of a linear scoring method of udder morphology for the selection scheme of Sardinian sheep. J. Dairy Sci.,v.89, p.2200-2209, 2006.

CLEMENT, V.; MARTIN, P.; BARILLET, F. Elaboration d'un index synthétique caprin combinant les caractères laitiers et des caractères de morphologie mammaire. Renc. Rech. Ruminants, v.13, p.209-212, 2006.

CONTRIBUIÇÕES das câmaras setoriais e temáticas à formulação de políticas públicas e privadas para o agronegócio. Brasília: Ministério da Agricultura, 2006 Disponível em: $<$ http://www.agricultura.gov.br/arq editor/LIVR O_COMPLETO.pdf $>$. Acessado em: $1 \overline{3} / 11 / 2014$.

DELLA LIBERA, A.M.M.P.; SOUZA, F.N.; BLAGITZ, M.G.; BATISTA, C. F. Avaliaçao de indicadores inflamatórios no diagnóstico da mastite bovina. Arq. Inst. Biol, v.78, p.297-300, 2011.

DUBE, B.; DZAMA, K.; BANGA, C.B.; NORRIS, D. An analysis of the genetic relationship between udder health and udder conformation traits in South African Jersey cows. Animal, v.3, p.494-500, 2009.

GOETSCH, A.L.; ZENG, S.S.; GIPSON, T.A. Factors affecting goat milk production and quality. Small Ruminant Res., v.101, p.55-63, 2011.

GOMES, V.; DELLA LIBERA, A.M.M.P.; MADUREIRA, K.M.; ARAÚJO, W.P. Effect of the stage of lactation on somatic cell counts in healthy goats (Caprae hircus) breed in Brazil. Small Ruminant Res., v.64, n.1-2, p.30-34, 2006.
KOOP, G.; DIK, N.; NIELEN, M.; LIPMAN, L.J.A. Repeatability of differential goat bulk milk culture and associations with somatic cell count, total bacterial count, and standard plate count. J. Dairy Sci., v.93, p.2569-2573, 2010.

MAGALHÃES, A.C.M. Obtenção higiênica e parâmetros de qualidade do leite de cabra. Viçosa: [s.n.], 2005. Disponível em: $<$ https://www.dti.ufv.br/dzo/caprinos/artigos_tec/ hig_quali.pdf $>$. Acessado em: 02/03/2015.

MANFREDI, E.; PIACERE, A.; LAHAYE, P.; DUCROCQ, V. Genetic parameters of type appraisal in Saanen and Alpine goats. Livest. Prod. Sci., v.70, p.183-189, 2001.

MAVROGENIS, A.P.; PAPACHRISTOFOROU, C.; LYSANDRIDES, P.; ROUSHIAS, A. Environmental and genetic effects on udder characteristics and milk production in Damascus goats. Small Ruminant Res., v.2, p.333-343, 1989.

MIRA, C.S.; DELLA LIBERA, A.M.M.P.; SOUZA, F.N.; BLAGITZ, M.G. Correlação entre a contagem automática de células somáticas e a porcentagem de neutrófilos pela citometria de fluxo e pela técnica de citocentrifugação. Arq. Bras. Med. Vet. Zootec., v.65, p.1403-1408, 2013.

MONTALDO, H.; MARTÍNEZ-LOZANO, F.J. Phenotypic relationships between udder and milking characteristics, milk production and California mastitis test in goats. Small Ruminant Res., v.12, p.329-337, 1993.

MONTALDO, H.H.; VALENCIA-POSADAS, M.; WIGGANS, G R. et al. Genetic and environmental relationships between milk yield and kidding interval in dairy goats. J. Dairy Sci., v.93, p.370-372, 2010.

PAAPE, M.J.; WIGGANS, G.R.; BANNERMAN, D.D.; et al. Monitoring goat and sheep milk somatic cell counts. Small Ruminant Res., v.68, p.114-125, 2007.

PERIS, S.; CAJA, G.; SUCH, X. Relationships between udder and milking traits in MurcianoGranadina dairy goats. Small Ruminant Res., v.33, p.171-179, 1999. 
PRODUÇÃO DA PECUÁRIA MUNICIPAL, v.38, 2010. Disponível em: $<$ http://www.ibge.gov.br/home/estatistica/econo $\mathrm{mia} / \mathrm{ppm} / 2010 / \mathrm{ppm} 2010 . \mathrm{pdf}>$. Acessado em: $01 / 03 / 2015$

RUPP, R.; BOICHARD, D. Genetic parameters for clinical mastitis, somatic cell score, production, udder type traits, and milking ease in first lactation Holsteins. J. Dairy Sci., v.82, p.2198-2204, 1999.

RUPP, R.; BOICHARD, D. Genetics of resistance to mastitis in dairy cattle. Vet. Res., v.34, p.671-688, 2003.

RUPP, R.; CLÉMENT, V.; PIACERE, A. et al. Genetic parameters for milk somatic cell score and relationship with production and udder type traits in dairy Alpine and Saanen primiparous goats. J. Dairy Sci., v.94, p.3629-3634, 2011.
SOUZA, G. .; FARIA, C. .; MORAES, L.C.D.; RUBIALE, L. Contagem de células somáticas (CCS) em leite de cabra. Panorama Leite, v.2, 2007.

SZYMANOWSKA, A.; PATKOWSKI, K.; MIDUCH, A.; MILERSKI, M. Correlation between mammary gland morphology and gland cistern size to lactation milk yield in goat. Annales Univ. Mariae Curie Skalodowska, v.28, p.36, 2010 .

TOVAR-LUNA, I.; PUCHALA, R.; SAHLU, T.et al. Effects of stage of lactation and level of feed intake on energy utilization by Alpine dairy goats. J. Dairy Sci., v. 93, p.4829-4837, 2010.

ZENG, S.S. Comparison of goat milk standards with cow milk standards for analyses of somatic cell count, fat and protein in goat milk. Small Ruminant Res., v.21, p.221-225, 1996. 